\title{
RECUPERAÇÃO FLORESTAL EM UMA ÁREA DEGRADADA PELA EXPLORAÇÃO DE AREIA NO DISTRITO FEDERAL
}

\author{
FOREST RESTORATION OF A DEGRADAD AREA BY SAND \\ EXPLOTATION IN THE FEDERAL DISTRICT, BRAZIL
}

\author{
RECUPERACIÓN DE ZONAS DEGRADADAS EN UN AREA DE \\ EXPLORACIÓN DE ARENA EN EL DISTRITO FEDERAL, BRAZIL
}

\author{
Fábio Venturoli \\ Engenheiro Florestal, mestre e doutor em Ciências Florestais \\ Escola de Agronomia e Engenharia de Alimentos/EA, Universidade Federal de Goiás/UFG. \\ Rodovia Goiânia - Nova Veneza Km 0, Campus Samambaia. Caixa Postal 131. 74690-900 - Goiânia, \\ E-mail: fabioventuroli@gmail.com
}

Sílvio Venturoli

Engenheiro Agrônomo, Brasília, DF.

E-mail: venturoli.silvio@gmail.com

\begin{abstract}
Resumo
Esta pesquisa tem como finalidade contribuir com a recuperação de áreas degradadas no bioma cerrado. A área estudada localiza-se no Distrito Federal e compreende um empreendimento de exploração de areia quartzítica sob cerrado sentido restrito, com desmatamento licenciado pelo IBRAM/DF. Foram investigadas a regeneração natural após a exploração da areia, em função do retorno da camada superficial do solo original (topsoil) à área, e a influência de um polímero hidroabsorvente na sobrevivência de mudas nativas do bioma cerrado plantadas com o objetivo de facilitar a restauração florestal. Os resultados indicaram uma mortalidade na comunidade plantada de $11 \% \mathrm{em}$ sete meses, valor considerado baixo e que pode ser relacionado à eficiência do polímero hidroretentor. A regeneração natural, ausente na ocasião do plantio, foi intensa na segunda avaliação, quando registrou-se o predomínio de Mimosa claussenii Benth. representando entre 26 e $50 \%$ de cobertura do solo. Os resultados sugerem a eficácia de retornar à área degradada a camada superficial do solo original, pois transporta material propagativo das plantas, o que facilita a restauração florestal; e a eficiência uso do polímero como condicionador de solo.

Palavras-chave: Cerrado, dinâmica florestal, cobertura do solo, condicionador de solo.
\end{abstract}

\begin{abstract}
This research aims to contribute to the recovery of degraded areas in the cerrado. The study site is located in the Federal District, Brazil, and includes quartzitic sand exploration under cerrado stricto sensu, with deforestation licensed by IBRAM/DF. Natural regeneration was investigated after the exploration of sand, due to the return of
\end{abstract}


the original surface soil layer (topsoil) to the area, and the influence of a hydrogel polymer on the survival of native seedlings planted with the objective to facilitate forest restoration. The results indicated a mortality in the community planted of $11 \%$ in seven months, considered low and may be related to the efficiency of hydrogel polymer. Natural regeneration, absent at the time of planting, was intense in the second evaluation, when it recorded a prevalence of Mimosa claussenii Benth, representing between 26 and 50\% soil cover. The results suggest the effectiveness of the degraded area back to the original topsoil, as transports cuttings from plants, which makes forest restoration, and the efficiency of using polymer as a soil conditioner.

Key-words: Cerrado, forest dynamics, soil cover, soil conditioner.

\section{Resumen}

Esta investigación tiene como objetivo contribuir con la recuperación de zonas degradadas incluye una empresa de exploración de arena cuarcíticas bajo cerrado stricto sensu, con la deforestación autorizada por IBRAM/DF. Se investigó la regeneración natural después de la exploración de arena, debido a la devolución de la capa superficial original del suelo (capa superficial) a la zona, y la influencia de un polímero hidroabsorbente en la supervivencia de las plántulas nativas del bioma cerrado con el fin de facilitar en el bioma cerrado. La zona de estudio se encuentra en el Distrito Federal y la restauración forestal. Los resultados indicaron una tasa de mortalidad en la comunidad plantado de $11 \%$ en siete meses, una cifra considerada baja y que puede estar relacionado con la eficiencia del polímero hidroretentor. La regeneración natural, ausente en el momento de la siembra, fue intensa en la segunda evaluación, al registrar el predominio de Mimosa claussenii Benth, que representan entre 26 y $50 \%$ de cobertura del suelo. Los resultados sugieren la eficacia de volver la zona degradada la capa superficial del suelo original, ya que transporta material propagativo de las plantas, lo que facilita la restauración forestal; y la eficiencia del uso del polímero como acondicionador del suelo.

Palabras-Clave: Cerrado, la dinámica forestal, cobertura del suelo,acondicionador del suelo.

\section{Introdução}

Áreas degradadas referem-se a alterações em um ecossistema natural (CORRÊA, 1998). Em geral apresentam baixa disponibilidade de nutrientes, baixa capacidade de retenção de água e alta compactação do solo, características que dificultam o desenvolvimento radicular das plantas e que impedem a regeneração natural.

O processo de regeneração natural é dinâmico, variável no espaço e no tempo e parte integrante do ciclo de desenvolvimento das florestas (RICHARDS, 1996). Com isto, o conhecimento do potencial de regeneração de uma área e dos fatores 
condicionantes é essencial para o sucesso de projetos de restauração da vegetação em áreas degradadas (HOSOKAWA et al., 1998).

A dinâmica da regeneração natural vai depender dos requerimentos por luz das espécies que persistem na área (WHITMORE, 1989). Algumas espécies são heliófitas (intolerantes à sombra), desenvolvendo-se somente em ambientes sob alta irradiação solar e outras são tolerantes à sombra e suas plântulas são capazes de sobreviver e alcançar a maturidade mesmo sob um dossel fechado (RICHARDS, 1996; SWAINE e WHITMORE, 1988). No entanto, naturalmente existe uma amplitude de sobrevivência de plântulas na sombra representada por um contínuo de tolerância, como discutido por Augspurger (1984) e por Souza e Válio (2001).

Assim, quando as condições ecológicas da área são adequadas a regeneração desenvolvese naturalmente. Mas, em áreas degradadas, devido à alteração das condições ecológicas, a intervenção antrópica é necessária para a recuperação e posterior restauração florestal, o que é feito principalmente com o plantio de mudas de espécies nativas da região.

Considerando que a exploração de recursos minerais está regulamentada na legislação brasileira e que deve ser feita segundo critérios definidos no processo de licenciamento ambiental, conforme consta na Resolução do Conselho Nacional de meio Ambiente - CONAMA n. 237 de 1997. As empresas mineradoras que possuem a licença de lavra têm por obrigação recuperar a área degradada pela mineração. Essa obrigação advém da necessidade de retenção de solo, contenção de erosão, manutenção da biodiversidade e da beleza cênica, sendo o plantio de mudas indicado para locais onde além da cobertura vegetal, foram também eliminados os meios de regeneração natural, como o banco de sementes, de plântulas, chuva de sementes e possibilidade de rebrota (FELFILI et al., 2008).

Adicionalmente, é essencial desenvolver tecnologias que contribuam ou que acelerem o processo de recuperação de áreas degradadas, facilitando a restauração florestal nessas áreas. Uma das tecnologias existentes refere-se ao uso de polímeros hidroabsorventes, amplamente disponíveis no mercado e que são adicionados às covas de plantio das mudas na forma hidratado.

Esses polímeros hidroabsorventes melhoram a capacidade do solo em reter água e nutrientes para as plantas, atuando como condicionadores de solo. Em contato com a água, esses polímeros absorvem as moléculas de água e formam rapidamente um gel. Capaz de armazenar muitas vezes seu próprio peso em água, os polímeros produzem numerosos ciclos de secagemirrigação por longo tempo de duração e são biodegradáveis, persistindo no solo por até cinco anos (VAN COTTEN, 1998).

Os condicionadores de solo têm contribuído para aumentar a capacidade de retenção de água do solo, reduzindo a frequência de irrigação e permitindo a utilização mais efetiva dos 
recursos solo e água, contribuindo para melhorar o rendimento das culturas, como discutido por (OLIVEIRA et al., 2004). Esses mesmos autores discutem ainda que no Brasil, alguns polímeros hidroabsorventes estão sendo utilizados na produção de frutas, hortaliças e mudas de diversas espécies, bem como na formação de gramados em jardins, campos de futebol e de golfe.

Além disso, sabe-se que esses polímeros hidroabsorventes são amplamente utilizados em plantios de reflorestamento, principalmente com as espécies do gênero Eucalyptus, em regiões onde há estacionalidade climática, com uma estação seca bem definida, como no Brasil Central.

No entanto, são raros os estudos no bioma cerrado envolvendo a utilização desses polímeros em plantios de espécies florestais nativas, tais como os plantios que compõem os Programas de Recuperação de Áreas Degradadas/PRAD's exigidos na legislação ambiental. Em um estudo preliminar e pioneiro, Souza et al. (2010) investigaram o efeito do uso de um polímero hidroabsorvente na sobrevivência de mudas de espécies florestais nativas do bioma cerrado, em um plantio de recuperação de área degradada. Os resultados não indicaram a eficiência do produto, ou seja, não houve diferença estatística significativa $(p<0,05)$ entre a sobrevivência das mudas sob o efeito do polímero e sem este, mas os autores discutiram que as avaliações foram relativas à estação chuvosa, quando, teoricamente, não há déficit hídrico no solo para as plantas, o que, portanto, interferiu nas análises da eficiência do polímero hidroabsorvente.

Nesse contexto, o presente trabalho teve como objetivo avaliar a influência de um polímero hidroadsorvente na sobrevivência de mudas nativas do bioma cerrado, de diferentes habitats de ocorrência preferencial, conforme Sano et al. (2008), plantadas em uma área em processo de recuperação florestal localizada em um empreendimento de exploração mineral de areia quartzítica sob cerrado sentido restrito, em Brasília, Distrito Federal.

O plantio das mudas seguiu o Modelo Nativas do Bioma, proposto e estudado por mais de vinte anos por pesquisadores de diversas Instituições de Pesquisa do Brasil Central (FELFILI, 2007). O Modelo Nativas do Bioma busca o plantio em áreas degradadas de cerrado de espécies do mosaico vegetacional do bioma como forma de acelerar o processo de recuperação, uma vez que as espécies arbóreas de ambientes florestais apresentam crescimento inicial mais rápido do que as espécies de cerrado típico, e com isso, recobrem mais rapidamente o solo e com o sombreamento reduzem a competição por gramíneas exóticas (FELFILI, 2007; PINTO et al., 2007).

Neste experimento a seguinte hipótese foi testada: polímeros hidroabsorventes são eficientes na sobrevivência de mudas nativas do cerrado em plantios de recuperação de áreas degradadas? 


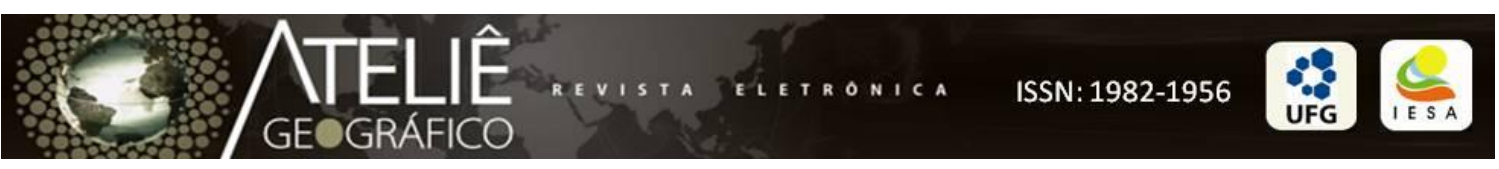

Este trabalho avaliou também a cobertura do solo por vegetação em regeneração natural na área em recuperação, verificando o estado de degradação da área e a capacidade do ambiente em se recuperar de forma natural, segundo as condições ecológicas locais e a presença de propágulos no local ou vindos de áreas próximas. A segunda hipótese testada neste estudo foi a seguinte: a área degradada pela exploração de areia quartzítica, quando recebe a camada superior do solo original (topsoil) apresenta alta capacidade de regeneração natural devido à presença no topsoil de propágulos de espécies com capacidade para se desenvolver na área?

Ao considerar as duas hipóteses de estudo, espera-se fornecer informações sobre a importância do retorno do topsoil à área degradada e fazer uma associação desta técnica com a técnica de recuperação com o plantio de mudas, verificando a eficiência de cada uma delas ou de ambas combinadas, na facilitação da restauração florestal.

\section{Metodologia}

\section{Área de estudo}

O estudo foi desenvolvido em uma área degradada pela exploração de areia quartzítica sob cerrado sentido restrito, localizada em na Região Administrativa de Sobradinho, em Brasília, Distrito Federal (1542’28” S; 4744’15” W). O empreendimento está devidamente licenciado pelo Instituto Brasília Ambiental/IBRAM/DF que é o Órgão competente e responsável pelo licenciamento no DF. A área pertence à União e está sendo explorada em regime de Concessão pela empresa Bracal, Brasília Calcário Agrícola Ltda., com sede em Brasília, DF.

A Licença de Operação do empreendimento prevê que cada lote explorado deve ser recuperado após a exploração, seguindo o Programa de Recuperação de Áreas Degradadas/PRAD elaborado para o empreendimento. O PRAD está sendo cumprido fielmente pelos empreendedores, no entanto, conforme as suas exigências, muitas questões merecem ser estudadas a fim de otimizar o processo de recuperação da área degradada e até mesmo para aumentar as chances ou diminuir o tempo da restauração florestal.

\section{Influência do polímero hidroabsorvente na sobrevivência de mudas nativas do cerrado}

O experimento foi montado em uma área de 1 hectare que, após a exploração de areia quartzítica, foi preparada para o plantio de mudas recobrindo-a com a camada superior do solo original (topsoil) que fora retirado antes da exploração e armazenado para esta finalidade. 
Depois de recobrir o solo, o terreno foi estabilizado topograficamente para evitar processos erosivos (Figura 1).

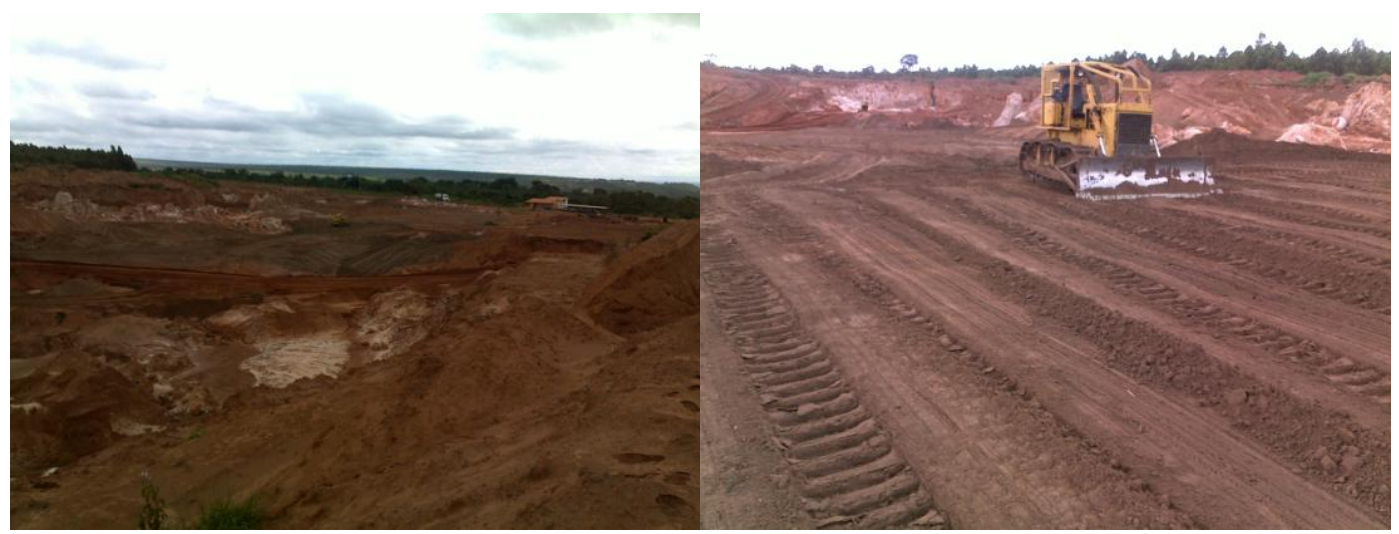

Figura 1. Preparo da área degradada para o plantio de mudas, recobrindo-a com a camada superior do solo original (topsoil) e estabilizando-a topograficamente (terraplenagem).

Em julho de 2009 foram plantadas no local 1.600 mudas de 14 espécies nativas do bioma cerrado, compreendendo uma equabilidade de 0,83 . O espaçamento entre as mudas foi de aproximadamente $3 \times 3 \mathrm{~m}$ e a adubação consistiu na aplicação de 1 litro de esterco de bovinos curtido, $150 \mathrm{~g}$ de N P K na formulação 4:14:8 e 50g de calcário dolomítico, por cova, adicionando-se ainda $400 \mathrm{ml}$ de polímero hidroretentor hidratado, conforme recomendação do fabricante do produto (HYDROPLAN-EB, 2009) (Figura 2).

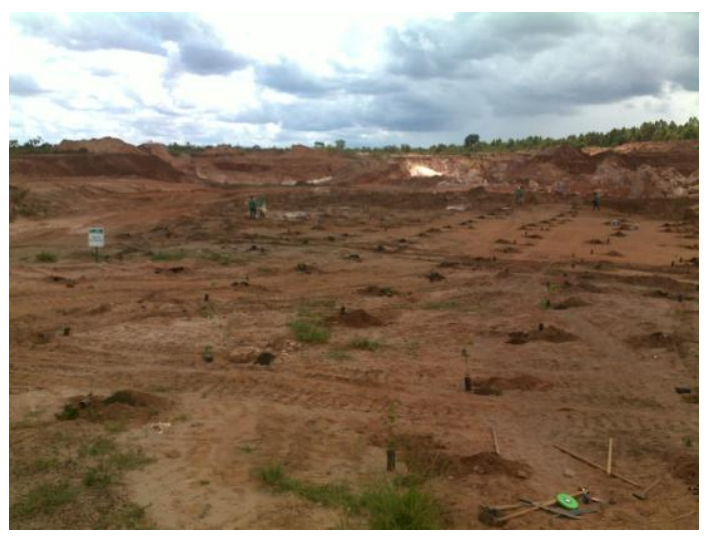

Figura 2. Plantio de mudas na área degradada em processo de recuperação florestal, no Distrito Federal.

Em fevereiro de 2010 avaliou-se a sobrevivência das mudas, contabilizando as plantas que permaneciam vivas sete meses após o plantio.

A taxa de mortalidade foi calculada pelo número remanescente de plantas em relação à quantidade inicial de mudas plantadas, conforme recomendado Sheil et al. (1995). 


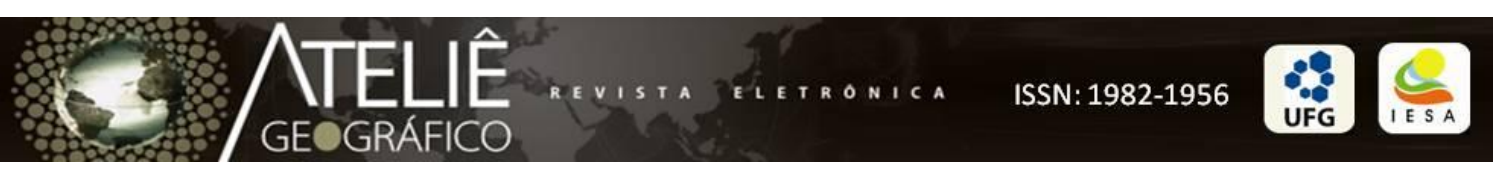

A análise de sobrevivência das mudas plantadas foi feita em nível de comunidade.

As espécies listadas no PRAD do empreendimento e plantadas na área em avaliação foram as seguintes, sendo indicado entre parênteses o habitat de ocorrência preferencial de cada uma, conforme Sano et al. (2008): Anadenanthera colubrina (florestas estacionais e matas de galeria), Myracrodruon urundeuva (florestas estacionais), Dipteryx alata (cerrado e florestas estacionais), Eugenia dysenterica (cerrado), Abarema cochlilacarpus (florestas estacionais e matas de galeria), Copaifera langsdorffii (cerrado, matas de galeria e florestas estacionais), Amburana cearensis (florestas estacionais), Inga edulis (matas de galeria), Handroanthus serratifolius (cerrado, matas de galeria e florestas estacionais), Handroanthus aureus (cerrado e florestas estacionais), Handroanthus roseoalbus (cerrado, matas de galeria e florestas estacionais), Handroanthus chrysotrichus (cerrado, matas de galeria e florestas estacionais), Cybistax antisyphilitica (cerrado e florestas estacionais), Hymenaea courbaril (matas de galeria).

\section{Regeneração natural}

A regeneração natural na área foi verificada estimando-se a porcentagem de solo coberto por vegetação natural, por forma de vida (gramíneas, ervas, arbustos e árvores), na ocasião do plantio e sete meses depois.

A cobertura do solo foi estimada utilizando uma escala de cobertura adaptada à de Braun-Blanquet (KENT e COKER, 1992) dividida em seis categorias: 0\%, 1-25\%, 26-50\%, 51$75 \%, 76-99 \%$ e $100 \%$. Para a avaliação foi utilizado um gabarito quadrado feito de madeira medindo 1 x $1 \mathrm{~m}$ na parte interna, subdividido em quatro partes. Este gabarito era lançado aleatoriamente entre as linhas de plantio, checando-se a suficiência amostral pela variância, com teste $t$-student, a 5\% de probabilidade (PELLICO NETTO e BRENA, 1997).

\section{Resultados e discussão}

\section{Influência do polímero hidroabsorvente na sobrevivência de mudas nativas do cerrado}

A mortalidade das mudas no período foi computada em $11 \%$, valor considerado baixo e que pode ser relacionado à eficiência do polímero hidroretentor, pois em geral, na região, esses plantios sem o uso do polímero apresentam mortalidade inicial próxima a $20 \%$. Além disso, não foi verificado o ataque das mudas por pragas e doenças e a mortalidade não ficou concentrada em nenhuma espécie, podendo então ser associada a fatores intrínsecos das plantas, a distúrbios 
provocados no torrão ou nas mudas, por ocasião do plantio ou à má formação da muda em viveiro.

Os resultados desta pesquisa são parecidos aos encontrados por Souza et al. (2010), mas apesar dos autores indicarem que não houve influência do polímero hidroabsorvente na sobrevivência das plantas, ou seja, a mortalidade de mudas não pôde ser associada à não utilização do condicionador de solo, as suas avaliações ocorreram somente na estação chuvosa, quando as plantas, teoricamente, não sofrem com estresse hídrico do solo. Situação um pouco diferente da encontrada nesta pesquisa, em que o plantio das mudas ocorreu na estação seca e a mortalidade foi considerada baixa, podendo neste caso estar relacionada à presença do polímero hidroabsorvente.

Em plantios florestais em recuperação de áreas degradadas, sem o uso de polímeros hidroabsorventes, geralmente, aceita-se como normal uma mortalidade de até $10 \%$ no primeiro ano após o plantio, se este for executado no início da estação chuvosa (MARTINS, 2009). Já o limite considerado aceitável para mortalidade pós-plantio em reflorestamentos comerciais é de $20 \%$ (MALINOVSKI et al., 2006), sendo o dobro do valor considerado na prospecção da viabilidade econômica do programa estadual de madeiras de Lei, do estado de São Paulo (CASTANHO FILHO, 2007), ambos também se forem executados no início da estação chuvosa. Portanto, mais uma vez a mortalidade de $11 \%$ encontrada neste estudo, que foi executado durante a estação seca, pode estar relacionada à eficiência do uso do polímero hidroabsorvente, pois, é nos estágios iniciais que as mudas plantadas mais necessitam de água para sobreviver, sendo esse um dos principais motivos para que os plantios florestais ocorram no início da estação chuvosa.

Sugere-se assim, realizar novas avaliações periódicas na área em experimentação, inclusive replantando as mudas mortas, para realmente verificar a eficiência do uso do condicionador de solo na sobrevivência plantas, recomendando ou não a sua utilização em projetos de recuperação de áreas degradadas e ou em programas de reflorestamentos comerciais.

É importante destacar ainda que o uso de polímeros hidroabsorventes apresenta custos elevados ao empresário ou produtor rural e que, portanto, a sua eficiência deve ser comprovada por estudos como este.

\section{Regeneração natural}

A regeneração natural, ausente na ocasião do plantio, foi intensa na segunda avaliação, sendo mais presente nos limites da área com o cerrado remanescente que ainda será desmatado para a exploração da areia quartizítica. 


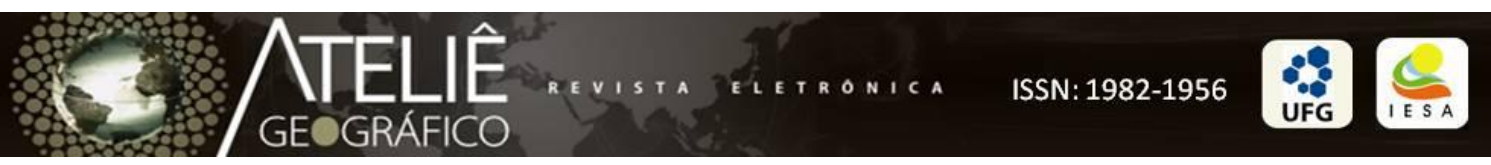

Registrou-se a regeneração de espécies arbóreas, provenientes de rebrotas, predominando Mimosa claussenii Benth.

A cobertura do solo estimada ficou entre 26 e 50\%, computando-se também as gramíneas nativas e exóticas na área, que ainda não foram identificadas em nível de espécie.

As rebrotas sugerem a eficácia de retornar à área degradada a camada superficial do solo original, pois transporta material propagativo das plantas, como raízes e galhos que possuem a capacidade de rebrotar; além de sementes, presentes no banco de sementes anterior à retirada do topsoil.

A combinação das duas técnicas foi considerada apropriada a este tipo de ambiente, pois, apesar de haver grande cobertura do solo por vegetação, de 26 a 50\%, houve um predomínio ou dominância de M. Claussenii, uma espécie arbustiva-arbórea com grande capacidade em rebrotar. Isso de certa forma reflete o estágio inicial de sucessão secundária da área, que está diretamente relacionada ao topsoil.

Complementarmente ao retorno do topsoil, o plantio de mudas pode acelerar a recuperação florestal, facilitando a sucessão ecológica. As mudas, aliadas à regeneração natural atraem a fauna, servindo como abrigo e poleiro, o que facilita o recrutamento de espécies vegetais pelo ingresso de sementes e ajuda na restauração florestal.

Em um estudo avaliando a regeneração natural no sub-bosque de uma floresta estacional em estágio avançado de sucessão secundária, Venturoli et al. (no prelo) encontraram muitos indivíduos de espécie arbóreas, inclusive de espécies de alto valor comercial madeireiro, o que demostra a grande capacidade das espécies florestais nativas em recolonizar em médio e longo prazos as áreas que sofreram alterações significativas da cobertura florestal. Além disso, é essencial estudar a regeneração natural, ao longo do tempo, em áreas que também sofreram alterações na estrutura do solo, como as deste estudo, verificando a capacidade de regeneração natural e a eficiência dos plantios na facilitação da recuperação florestal.

Os resultados desta pesquisa vão auxiliar a empresa Bracal em seu programa ambiental de recuperação de áreas degradadas pela exploração de areia quartzítica. Contudo, deve-se lembrar que esta pesquisa de restauração florestal é uma pesquisa em longo prazo, devendo ser acompanhada periodicamente até que resultados mais confiáveis possam ser obtidos.

Destaca-se ainda que esta pesquisa pode fornecer informações para auxiliar a formulação de legislações específicas visando reflorestamentos e recuperação de áreas degradadas no Brasil Central, em áreas com características ambientais semelhantes, de forma a contemplar os pressupostos ligados à restauração ecológica que foram relacionados e amplamente discutidos por Durigan et al. (2010). 


\section{Conclusão}

Os resultados demonstraram que é possível acelerar o restabelecimento da integridade ecológica de áreas degradadas pela mineração a partir do retorno da camada superficial do solo à área degradada e pelo plantio de mudas nativas.

O polímero hidroretentor utilizado mostrou-se eficiente, evitando a mortalidade das mudas na estação seca do ano e pode também contribuir com o processo de restauração florestal de áreas degradadas.

O Modelo Nativas do Bioma sugere que o bioma cerrado pode ser recuperado em grande escala, misturando-se espécies nativas da região, com benefícios socioeconômicos e ambientais. Além disso, espera-se uma rápida cobertura do terreno, o que além de reduzir os custos de manutenção, gratifica os responsáveis pela recuperação e estimula novas iniciativas, dinamizando, dessa forma, a recuperação das áreas degradadas do Cerrado e agregando uma função econômica e social, além da ecológica, o que facilita a restauração florestal desses ambientes.

\section{Agradecimentos}

Às Instituições de fomento: CNPq - Processo número 561823/2010-3, Edital MCT/CNPq/CTAgronegócio No 26/2010; BRACAL - Brasília Calcário Agrícola Ltda. e MATAVIRGEM produção e comércio de mudas Ltda. ME.

Instituição de Apoio: Universidade Federal de Goiás - UFG, Escola de Agronomia e Engenharia de Alimentos - EA.

\section{Referências bibliográficas}

AUGSPURGER, C.K. Likght requirements of neotropical tree seedling: a comparative study of growth and survival. Journal of Ecology, London, v. 72, n. 3, p. 777-795, 1984.

CASTANHO FILHO, E. P. Prospecção da viabilidade econômica do programa estadual de madeiras de Lei. Informações Econômicas, São Paulo, v. 37, n. 3, p. 14-26, 2007.

CORRÊA, R. S. Degradação e Recuperação de Áreas no Distrito Federal. In: CORRÊA, R. S.; MELO FILHO, B. (Orgs.) Ecologia e Recuperação de áreas degradadas no cerrado. Brasília, DF: Paralelo 15, 1998. p. 13-20. 
DURIGAN, G.; ENGEL, V. L.; TOREZAN, J. M.; MELO, A. C. G.; MARQUES, M. C. M.; MARTINS, S. V.; REIS, A.; SCARANO, F. R. Normas jurídicas para a restauração ecológica: uma barreira a mais a dificultar o êxito das iniciativas? Revista Árvore,

Viçosa, v. 34, n. 3, p. 471-485, 2010.

FELFILI, J. M. Recuperação de áreas degradadas no Cerrado, com espécies nativas do Bioma: Quebrando Paradigmas. Revista Opiniões, São Paulo, v. 7, 2007.

FELFILI, J. M.; FAGG, C. W.; PINTO, J. R. R. Recuperação de áreas degradadas. In: FELFILI, J. M.; SAMPAIO, J. C.; CORREIA, C. R. M. A. (Orgs.) Conservação da natureza e recuperação de áreas degradadas na bacia do São Francisco: treinamento e sensibilização. Brasília, DF: Centro de Referência em Conservação da Natureza e Recuperação de Áreas Degradadas/CRAD, 2008. 96p.

HOSOKAWA, R. T.; MOURA, J. B.; CUNHA, U. S. Introdução ao manejo e economia de florestas. Curitiba: UFPR, 1998. 162p.

HYDROPLAN-EB. Recomendação de uso do hydroplan-EB. Newsletter Hidroplan-EB, São Paulo, v. 4, n. 3, p. 2, 2009.

KENT, M.; COKER, P. Vegetation Description and analysis: a Practical Approach. London: Belhaven Press, 1992.363p.

MALINOVSKI, R. A.; BERGER, R.; SILVA, I. C.; MALINOVSKI, R. A.; BARREIROS, R. M. Viabilidade econômica de reflorestamentos em áreas limítrofes de pequenas propriedades rurais no município de São José dos Pinhas, PR. Floresta, Curitiba, v. 36, n. 2, p. 261-274, 2006.

MARTINS, E. Passo-a-passo para obter sucesso no plantio de Eucalipto. Newsletter Hidroplan-EB, São Paulo, v. 2, n. 1, p. 1, 2009.

OLIVEIRA, R. A.; REZENDE, L. S.; MARTINEZ, M. A.; MIRANDA, G. V. Influência de um polímero hidroabsorvente sobre a retenção de água no solo. Revista Brasileira de Engenharia Agrícola e Ambiental, Campina Grande, v. 8, n. 1, p. 160-163, 2004. 
PÉLLICO NETTO, S.; BRENA, D. A. Inventário Florestal. Curitiba, PR: PÉLLICO NETTO, S.; BRENA, D. A (Eds.), 1997. 316p.

PINTO, J. R.; CORREIA, C. R.; FAGG, C. W.; FELFILI, J. M. Sobrevivência de espécies vegetais nativas do cerrado, implantadas segundo o modelo MDR cerrado para recuperação de áreas degradadas. In: CONGRESSO DE ECOLOGIA DO BRASIL, VIII. Caxambu, 2007. Anais. Caxambu, MG.

RICHARDS, P. W. The tropical rainforest: an ecological study. $2^{\text {nd }}$ edition. Cambridge: Cambridge University Press, 1996. 575p.

SANO, S. M.; ALMEIDA, S. P.; RIBEIRO, J. F. Cerrado: ecologia e flora. Brasília: Embrapa, 2008. v. 2, 1279p.

SHEIL, D.; BURSLEM, D.F.R.P.; ALDER, D. The interpretation and misinterpretation o mortality rate measures. Journal of Ecology, London, v. 83, p. 331-333, 1995.

SOUZA, D. M.; RESENDE, I. M. H.; CAMPOS, A. S.; CALIL, F. N.; BARREIRA, S.; BORGES, J. D.; TELES, H. F.; VENTUROLI, F. Influência de polímero hidroabsorvente na sobrevivência de mudas nativas do cerrado em plantio de recuperação de área degradada. CONGRESSO DE PESQUISA, ENSINO E EXTENSÃO DA UFG. Goiânia, GO, 18 a 22 de outubro de 2010. Anais. Goiânia: UFG, 2010.

SOUZA, R. P.; VÁLIO, I. F. M. Seed size, seed germination, and seedling survival of Brazilian tropical tree species differing in sucessional status. Biotropica, Washington, v. 33, n. 3, p. $447-$ 457, 2001.

SWAINE, M.D.; WHITMORE, T.C. On the definition of ecological species groups in tropical rain forests. Vegetatio, New York, v. 75, p. 81-86, 1988.

VAN COTTEN, W. TerraCottem no combate à poluição ou contaminação do solo. Relatório de aplicação, 1998. Disponível em: 〈http://www.terracottem.com>. 
VENTUROLI, F.; FAGG, C. W.; FELFILI, J. M. Avaliação temporal da regeneração natural em uma floresta estacional semidecídua secundária, sob manejo, em Pirenópolis, Goiás. Revista Árvore, no prelo.

WHITMORE, T.C. Canopy gaps and the two major groups of forest tree. Ecology, New York, v. 70, n. 3, p. 536-538, 1989.

Recebido para publicação em outubro de 2010 Aprovado para publicação em dezembro de 2010 